\title{
Acquisition of general competences using project-based learning
}

\section{Laport, Francisco; Dapena, Adriana; Castro, Paula M. and Vazquez-Araujo, Francisco J.}

Computer Engineering Department, Universidade da Coruña, Spain.

\begin{abstract}
During years, professors of higher education focused on the outcome of the assimilation of information through learning (i.e., in the acquisition of knowledge). In a European context, the Bologna Process has accelerated and spread the process of defining explicit learning outcomes for higher education programs, including those in terms of general competences and transferable skills.

Our teaching experience in engineering degrees have shown that these students have difficulties for understanding the math basics of some disciplines. For greater effectiveness in knowledge acquisition, we consider as an essential issue the inclusion of laboratory activities based on computer simulations performed using software. For acquiring those general competences and transferable skills, our proposal also includes several projects in which our students must develop skills such as communication, teamwork or problem solving. We have observed that such projects allow students the development of their creativity, an improvement in oral and written communication, and also an optimal training for the B.S. degree project work and even for their future professional life.
\end{abstract}

Keywords: Bologna Process; competences; engineering degrees; projectbased learning; transferable skills. 


\section{Introduction}

The "Developing future skills in higher education" report, elaborated by the European Commission, distinguishes between knowledge, skills, and competences. Knowledge is defined as the outcome of the assimilation of information through learning. Skill means the ability to apply knowledge and use know-how for completing tasks and solving problems (which can be cognitive or practical). This report also classifies the main skills relevant for higher education students in three groups: the first one, cognitive skills (analytical, critical, reflective, creative thinking); the second group, methodological skills (time management, problem-solving, decision-making, learning strategies, planning, and digital skills), and finally, social skills (interpersonal communication, teamwork, conflict management and negotiation, intercultural understanding). Competence means the proven ability to use knowledge, skills, and personal, social and/or methodological abilities, in work or study situations for professional and personal development. The EACEA/Eurydice (2014) considers that in a competence-centered curricula the role of the higher education is "to develop the skills and competences of graduates necessary to find a job". However, this objective is not a simple task.

The Engineering Subject Centre (2005) recommended different teaching styles for developing skills and general competences, for example, role-play, research exercises and study cases. However, it does not discuss curriculum-wide teaching strategies which could include examples or practical exercises. Chadha (2006) presents a model of curriculum development which can be adapted to fit a teaching framework for the development of skills at undergraduate level. Some recent papers (see Sonseca et al (2015) and Rutten et al. (2012)) show how to design courses for acquiring general competences and main skills. The contribution of this paper is the design of such a course throughout our experience in engineering degree courses.

We have observed that the students of the Bachelor of Science degree in Computer Engineering and Computer Science have difficulties with the understanding of math basics used in several disciplines. We are critical about the traditional model based on theoretical lectures in which definitions and exercises are explained from a theoretical point of view. According to our background, we can say that the combination of both visual learning with conceptual learning is much more effective than that only using non-visual learning strategies. Therefore, we propose a change in the learning process towards Project-Based Learning (PBL) (Thomas (2000)) using technology-based tools. For such a purpose, and from an engineering and applied perspective, in recent years we have developed different laboratory activities based on computer simulations performed using software tools such as Matlab/Simulink or similar. These activities have been designed not only focusing on writing code for a specific task, but also on testing the students' comprehension about the 
materials previously covered by means of traditional theoretical lectures. We also propose different projects oriented to exploit the "rich world" of signal processing moving away from the idea of tasks strictly based on doing code.

In this paper, we will show a set of projects designed according to the idea that students can be able to achieve the specific competences established for a course in Digital Information Processing, but also transferable skills and general competences associated to higher education. Notice that both theoretical and laboratory activities are related to the acquisition of knowledge and specific competences, while projects are clearly designed to acquire those general competences.

This paper is organized as follows. In section 2, we show general ideas for two theoretical lessons. Section 3 includes the experimental activities, and Section 3 describes our proposals for the projects afore mentioned. Finally, Section 4 is devoted to some conclusion remarks.

\section{Theoretical Lessons}

Digital information processing is referred to gather, manipulate, store, retrieve, and classify recorded information. In computing, this information processing includes the use of algorithms for data transforming and/or manipulating. These concepts are studied throughout several courses of the Bachelor of Science degree in Computer Engineering and Computer Science.

In this section we will show two lessons used in the subject Digital Information Processing corresponding to the third year of this degree. Each lesson lasts two hours fully devoted to theoretical concepts and plus an additional hour for solving problems.

\subsection{Lesson 1: Signal Transforms}

The content of this lesson begins with the explanation of one-dimensional transforms and their properties. Transform theory has played a key role in many data processing areas for many years, and it continues to be a hot topic of great interest in both theoretical and applied works.

Although only some of these transforms are explained in detail throughout those theoretical lectures, we emphasize the Fourier transform because of its wide range of applications. Therefore, this lesson will be organized as follows,

1) Introduction to the Fourier transform.

2) The discrete Fourier transform.

3) Properties of the discrete Fourier transform.

4) Other transforms: Discrete Cosine transform and Hadamard transform. 


\subsection{Lesson 2: Signal Classification}

The material of this lesson is mainly oriented to the introduction in machine learning as well as its possible applications to the field of digital information and signal processing. It is important to say that there is another course of this degree devoted to delve into these concepts.

Both machine learning and data mining have become in recent years very relevant disciplines in the computation area. Moreover, their good performance for Big Data analysis and knowledge extraction promises a great future for both paradigms. We focus on a lesson devoted to the fundamental aspects of machine learning and to the math basics of simple classification algorithms. Our proposal also includes the applicability of statistical concepts for the extraction of significant features of the signals.

Therefore, this theoretical lesson will be organized as follows,

1) Introduction to Machine Learning.

2) Supervised versus unsupervised learning.

3) Feature extraction and dimensionality reduction, which is known as Principal component analysis (PCA).

4) Simple classifiers: k-Nearest Neighbors (KNN), Linear Discriminant Analysis (LDA), and so on.

\section{Laboratory Activities}

We have observed that our students of the Bachelor of Science degree in Computer Engineering and Computer Science usually consider the laboratory lectures as activities where writing code is the objective task. However, we are interested in the interpretation of results as a means of applying theory to practice. For this reason, we provide material as a guide for the practical activities to be done by students.

Each laboratory activity is scheduled to two hours. In each session our students must answer a simple questionnaire designed to determine their knowledge acquisition.

\subsection{Laboratory Activity 1: Filtering}

In this activity we propose that the students develop software using Octave or Matlab to observe the effect of different filters. Our objective is the understanding of the relationship between time and frequency-domain using simple examples.

For this purpose, we provide a tutorial with a general scheme of filtering in the frequencydomain. Figure 1 shows a summary of this scheme for guiding the student work, and is given by the following steps, 
1) Generate a sine signal.

2) Transform the signal to the frequency-domain.

3) Generate low-pass filters with different cut frequency.

4) Filter signals using these low-pass filters.

5) Apply the inverse Fourier transform for signal recovering.

For each step, we provide code snippets and examples. Then, the student uses this code to generate the sum of sine signals and filters them using low- and high-pass filters. As an example, we propose the filtering of recorded music to simulate quality of AM and FM. Finally, the visual representation and the audition of both the original and the recovered signals allow students the observation of the influence of each filter.

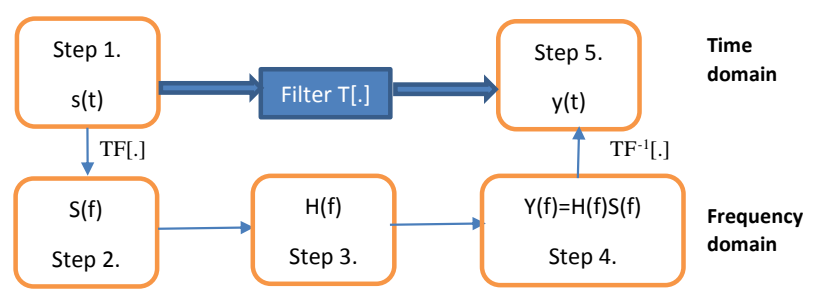

Figure 1: Summary of the tutorial about Fourier transform.

\subsection{Laboratory Activity 2: Signal Classification}

Following the same approach as done in Lesson 1, the objective of this practical exercise is again not only to write some code, but an adequate analysis of results. After that, the student should be able to understand the importance of extracting interpretable knowledge from previously incomprehensible data and of recognizing the huge variety of problems and real situations for its use. For this reason, we provide material as a guide for the student in these practical sessions.

For this purpose, we give a tutorial with the necessary steps to classify simple data using supervised algorithms. Figure 2 summarizes the main sections appeared in that tutorial. In it, each step is presented and explained together with a code snippet, as follows,

1) Given two patterns, randomly vary frequency and/or amplitude to generate 200 training sine signals for each pattern.

2) Extract statistics from the generated signals (mean, standard deviation, maximum value, minimum value, etc.) as features for their classification.

3) Create and train several classifiers with the selected features (LDA, Quadratic Discriminant Analysis or QDA, Support Vector Machine or SVM). These classifiers are given as functions of Octave or Matlab.

4) Generate a minimum number of 200 test signals of each class. 
5) Classify these signals using the previously obtained classifiers.

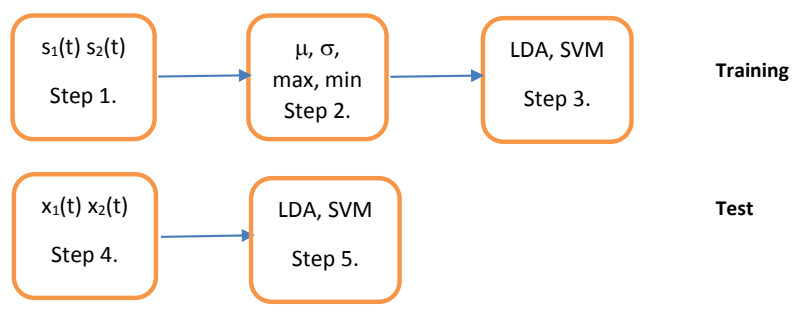

Figure 2: Summary of the tutorial about signal classification.

Following the tutorial, the student can be able to classify the signals considering two or more features. Finally, our students must evaluate the performance of each classifier using well-known metrics. For a better understanding, we also ask them to propose some experiments whose performance be bad, medium or high in terms of classification results.

\section{Proposed projects}

We consider that the courses for all the education levels, but especially in higher education, must be designed in order to guarantee that students achieve some important cognitive, methodological, and social skills. For this reason, we have proposed several projects with the following characteristics,

- The project is done by groups of three students, which allows us to obtain social skills like interpersonal communication, teamwork, conflict management, or negotiation.

- The professor provides the project idea while the student creates the framework (defines final objectives, selects software, etc.) which develops cognitive skills, such as creative thinking, and methodological skills, such as time management, problem-solving, decision-making, learning strategies, planning or digital skills.

- The students must present to the audience the projects following the rules for the B.S. degree final work by means a written document and an oral defense. One student of each group defends the oral work. The other two students and the professor form a tribunal that evaluates this defense using the rubrics in Table 1, where we define eight items of evaluation. The first two items are related to the content of the presentation/report; the third of them is devoted to determine the presentation/report's quality from the students' critical reasoning; the fourth one evaluates the additional resources used throughout the presentation/report; the fifth item controls the presentation time; the next two items describe how the student 
communicates the topic to the audience and finally, the last item tests the student's knowledge achievement by means of their answers to tribunal's questions. For writing communications skills, additionally to the first common four items, we include the report correction in terms of written language. Both rubrics for the evaluation of oral and written communication skills define a range between 1 and 4 of acquisition of these skills, corresponding respectively to poor and excellent levels. As a result, the highest qualifications are respectively 32 and 20 points. Table 2 defines the values range that determines the achievement level of those skills.

This type of evaluation provides the acquisition of cognitive skills, and it is also a good training for future oral communications in their academic or professional life.

- The professor initially recommends several printed references, although the student must look for information using other sources, especially the digital ones. This is strongly connected to the methodological skills.

Thus, we present the following projects to the students.

\subsection{Project 1: Photo Retouching}

The general idea is the design of an application for photo retouching using 2D filtering (smoothing, enhancing, etc.). In this project, the student must look for information about 2D transforms, which is an extension of the lesson devoted to signal transforms, as explained in Subsection 2.1. We will recommend the book of González et al. (2002), for example.

\subsection{Project 2: Image Compression}

The idea is the design of software for image compression. The students must investigate about the utilization of 2D transforms in JPEG and MPEG. It is especially interesting to compare DCT and Hadamard transforms. It is also necessary to understand the theoretical concepts of quantization and coding. The recommended book could be the same as before.

\subsection{Project 3: Detection of Pathologies}

The ElectroEncephaloGraphy (EEG) signals can be used to detect certain pathologies in sick patients. The idea of this project is the creation of a machine learning algorithm to classify data of real patients. The student should look for information about preprocessing techniques and signal analysis in EEG, which is also connected to the lesson devoted to signal transform (see Subsection 2.1). Moreover, the search of algorithms convenient for EEG classification is also mandatory, which is related to the introduction of machine learning done in the corresponding lesson proposed in Subsection 2.2. For this task, we recommend the book of Cohen (2014) and the data set provided in Andrzejak et al. (2001). 
Table 1: Rubric for oral and written communication skills.

\begin{tabular}{|c|c|c|c|c|}
\hline & Low (1p.) & Medium (2p.) & $\operatorname{High}(3 p)$. & Excellent (4p.) \\
\hline $\begin{array}{c}\text { Content } \\
\text { (Both) }\end{array}$ & Incomplete & $\begin{array}{l}\text { Complete, badly } \\
\text { motivated and } \\
\text { concluded; } \\
\text { technically poor }\end{array}$ & $\begin{array}{l}\text { Complete, } \\
\text { correctly } \\
\text { motivated and } \\
\text { concluded; } \\
\text { technically poor }\end{array}$ & $\begin{array}{l}\text { Complete, } \\
\text { correctly } \\
\text { motivated and } \\
\text { concluded; } \\
\text { technically good }\end{array}$ \\
\hline $\begin{array}{l}\text { Organization, } \\
\text { structure (Both) }\end{array}$ & $\begin{array}{c}\text { Disorganized } \\
\text { and illogically } \\
\text { sequenced }\end{array}$ & $\begin{array}{l}\text { Only partially } \\
\text { organized and } \\
\text { sequenced }\end{array}$ & $\begin{array}{c}\text { Mostly } \\
\text { organized and } \\
\text { sequenced }\end{array}$ & $\begin{array}{l}\text { Organized and } \\
\text { logically } \\
\text { sequenced }\end{array}$ \\
\hline $\begin{array}{l}\text { Critical } \\
\text { reasoning } \\
\text { (Both) }\end{array}$ & None & Limited & $\begin{array}{c}\text { Well done but } \\
\text { incomplete }\end{array}$ & $\begin{array}{c}\text { Well done } \\
\text { emphasizing } \\
\text { relevant aspects }\end{array}$ \\
\hline $\begin{array}{c}\text { Additional } \\
\text { resources } \\
\text { (Both) }\end{array}$ & Not included & $\begin{array}{l}\text { Limited, } \\
\text { irrelevant }\end{array}$ & $\begin{array}{c}\text { Mostly effective } \\
\text { and relevant }\end{array}$ & $\begin{array}{c}\text { Effective, high } \\
\text { quality } \\
\text { resources }\end{array}$ \\
\hline $\begin{array}{l}\text { Time } \\
\text { (Oral) }\end{array}$ & Not adjusted & $\begin{array}{l}\text { Adjusted but } \\
\text { incorrectly } \\
\text { distributed }\end{array}$ & $\begin{array}{l}\text { Adjusted and } \\
\text { correctly } \\
\text { distributed }\end{array}$ & $\begin{array}{l}\text { Adjusted and } \\
\text { correctly } \\
\text { distributed, even } \\
\text { dynamically }\end{array}$ \\
\hline $\begin{array}{c}\text { Corporal } \\
\text { language (Oral) }\end{array}$ & $\begin{array}{c}\text { No visual } \\
\text { contact; wrong } \\
\text { gestures }\end{array}$ & $\begin{array}{l}\text { Partial visual } \\
\text { contact; right } \\
\text { gestures }\end{array}$ & $\begin{array}{l}\text { Mostly visual } \\
\text { contact; right } \\
\text { gestures }\end{array}$ & Correct \\
\hline $\begin{array}{l}\text { Expression } \\
\text { (Oral) }\end{array}$ & $\begin{array}{c}\text { Poor } \\
\text { vocabulary, not } \\
\text { clear; wrong } \\
\text { tone }\end{array}$ & $\begin{array}{l}\text { Mostly poor } \\
\text { vocabulary, } \\
\text { clear; wrong } \\
\text { tone }\end{array}$ & $\begin{array}{l}\text { Mostly rich } \\
\text { vocabulary, } \\
\text { clear; mostly } \\
\text { correct tone }\end{array}$ & $\begin{array}{c}\text { Rich } \\
\text { vocabulary, } \\
\text { clear; right tone }\end{array}$ \\
\hline $\begin{array}{l}\text { Interaction } \\
\text { (Oral) }\end{array}$ & None & $\begin{array}{l}\text { Answers with } \\
\text { some doubts }\end{array}$ & $\begin{array}{l}\text { Mostly answers } \\
\text { without doubts }\end{array}$ & $\begin{array}{c}\text { Correct answers } \\
\text { even creating } \\
\text { debate }\end{array}$ \\
\hline $\begin{array}{l}\text { Language } \\
\text { (Written) }\end{array}$ & $\begin{array}{c}\text { Poor } \\
\text { vocabulary; } \\
\text { grammatical } \\
\text { errors and } \\
\text { misspellings }\end{array}$ & $\begin{array}{l}\text { Mostly poor } \\
\text { vocabulary, } \\
\text { some } \\
\text { grammatical } \\
\text { errors and } \\
\text { misspellings }\end{array}$ & $\begin{array}{c}\text { Mostly rich } \\
\text { vocabulary and } \\
\text { correct language }\end{array}$ & Correct \\
\hline
\end{tabular}


Laport, F.; Dapena, A.; Castro, P.; Vazquez-Araujo, F.

Table 2: Range for determining acquisition level of oral and written communication skills.

\begin{tabular}{|c|c|c|c|c|}
\hline & Low & Medium & High & Excellent \\
\hline Oral skills & $1-10$ & $11-20$ & $21-30$ & $31-32$ \\
\hline Written skills & $1-6$ & $7-12$ & $13-18$ & $19-20$ \\
\hline
\end{tabular}

\subsection{Project 4: Creation of Electronic Musical Instruments}

Since our students also follow other courses covering Arduino design, we propose the design of a custom sensor-based electronic musical instrument composed of three elements: sensors, an acquisition device, and a synthesis environment. This additive synthesis is directly related to FM and AM modulation that describes a signal as a combination of elementary trigonometric functions (see Subsection 3.1).

\section{Conclusions}

In this paper we introduced two lessons for a course of Digital Information Processing. Since students suffer from difficulties to solve problems directly associated to theory, but not to understand their real applications, we proposed four projects oriented to develop work general skills, including oral and written communication skills. The impact of this proposal on student evaluation is expected to be in terms of better rates and higher number of students attending the exam. Moreover, for further courses we will incorporate the "flipped classroom" methodology using videos for teaching theoretical contents, thus gaining time potentially used for doing problems or practical activities and projects.

\section{Acknowledgments}

This work has been funded by the Xunta de Galicia (ED431C 2016-045, ED341D R2016/012, ED431G/01), the Agencia Estatal de Investigación of Spain (TEC2015-69648REDC, TEC2016-75067-C4-1-R) and ERDF funds of the EU (AEI/FEDER, UE).

\section{References}

Andrzejak, R. G., Lehnertz, K., Mormann, F., Rieke, C., David, P., \& Elger, C. E (2001). Indications of nonlinear deterministic and finite-dimensional structures in time series of brain electrical activity: Dependence on recording region and brain state. Physical Review E, 64(6). 
Chadha, D. (2006). A curriculum model for transferable skills development. Engineering Education, 1(1), pp. 16-24.

Cohen, M. X. (2014). Analyzing neural time series data: theory and practice. MIT Press.

EACEA/Eurydice (2014). Modernisation of Higher Education in Europe: Access, Retention and Employability 2014. Eurydice Report. Luxemburg Publications Office. http://eacea.ec.europa.eu/education/eurydice/documents/thematic_reports/165EN.pdf.

Engineering Subject Centre (2005). Engineering Subject Centre guide: Supporting key skills in engineering. UK: The Higher Education Academy Engineering Subject Centre.

González, R. C., Woods, R. E. (2002). Digital Image Processing. Prentice HallInternational Edition.

Rutten N., van Joolingen W. R., van der Veen J. T. (2012). The learning effects of computer simulations in science education. Computers \& Education, 58(1), pp. 136153.

Thomas, J. W. (2000). A review of research on project-based learning. San Rafael, CA: Autodesk Foundation, 13, 1-45. 